\title{
12 Ammonia Reserve Batteries
}

A range of these batteries is supplied by Honeywell, who state that with the increased acceptance of lithium-based systems in the reserve battery field, the development of the ammonia battery has been allowed to decline in recent years.

The ammonia reserve battery does have an advantage over lithium-based systems in a limited number of high-current short-life applications where shelf life is important and operation at -54 to $+74{ }^{\circ} \mathrm{C}$ is required with a fast rise time. The Honeywell G2695B ammonia reserve battery (figure 12.1) is designed to run at $500 \mathrm{~mA}$ for 10 minutes at approximately $7.5 \mathrm{~V}$. It is used to power the XM-811 timer on the Lance missile. The Honeywell G25114 ammonia reserve battery provides $1.4 \mathrm{~mA}$ h capacity at a 3.8 average voltage.

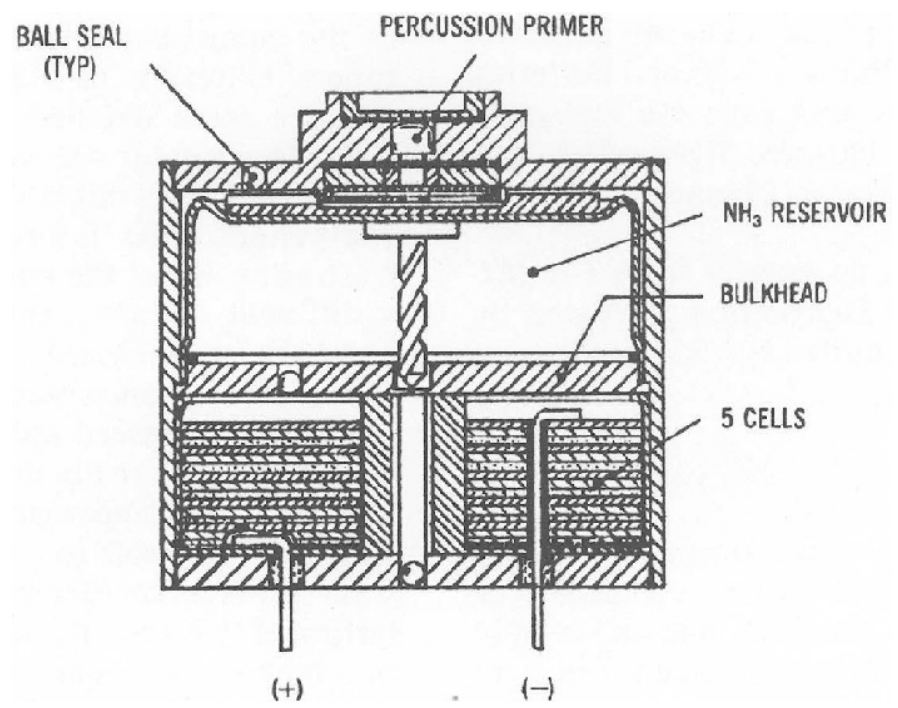

Figure 12.1 Typical liquid ammonia battery, Honeywell design 